\title{
Playbacks of predator vocalizations reduce crop damage by ungulates
}

\author{
Anna Widén $^{\text {a, }}$, Michael Clinchy ${ }^{\mathrm{b}}$, Annika M. Felton ${ }^{\mathrm{c}}$, Tim R. Hofmeester ${ }^{\mathrm{a}}$, Dries P.J. Kuijper ${ }^{\mathrm{d}}$, \\ Navinder J. Singh $^{\text {a, }}$, Fredrik Widemo ${ }^{\text {a, }}$, Liana Y. Zanette ${ }^{\text {b, } 1}$, Joris P.G.M. Cromsigt ${ }^{\text {a,e, } 1}$ \\ ${ }^{a}$ Department of Wildlife, Fish and Environmental Studies, Swedish University of Agricultural Sciences, 90183 Umeå, Sweden \\ ${ }^{\mathrm{b}}$ Department of Biology, Western University, London ON N6A 5B7, Canada \\ ${ }^{c}$ Southern Swedish Forest Research Centre, Swedish University of Agricultural Sciences, PO Box 190, SE-234 22 Lomma, Sweden \\ ${ }^{\mathrm{d}}$ Mammal Research Institute, Polish Academy of Sciences, Białowieża, Poland \\ ${ }^{\mathrm{e}}$ Centre for African Conservation Ecology, Department of Zoology, Nelson Mandela University, 6031 Port Elizabeth, South Africa
}

\section{A R T I C L E I N F O}

\section{Keywords:}

Crop damage

Landscape of fear

Ungulate management

Predator-induced fear

Playback experiment

\begin{abstract}
A B S T R A C T
Wild ungulates are a major consumer of agricultural crops in human dominated landscapes. Across Europe, ungulate populations are leading to intensified human-wildlife conflicts. At the same time, ungulates play a vital role in the structuring and functioning of ecosystems, and are highly appreciated for recreational hunting. Thus, managers often face the challenge of maintaining the benefits of having thriving ungulate populations while simultaneously minimizing their negative impacts. Broadcasting playbacks of predator vocalizations (e.g. dogs barking, wolves howling or humans talking) could potentially be used to induce fear and thereby displace or steer behavior of ungulates from conflict-prone sites resulting in reduced visitation and foraging time and consumption. Predator playback experiments in wilderness areas have repeatedly demonstrated to reduce the preys' resource use and impacts on the surrounding landscape, but this has not been tested in agricultural fields where human-ungulate conflicts are most pronounced. We responded to this need by conducting a predator playback experiment in multiple crop fields in southern Sweden, where multiple ungulate species (fallow deer, roe deer, red deer, moose, wild boar) coexist, using a novel integrated camera trap - speaker system (ABRs) that broadcasts sounds of choice when a camera is triggered by an ungulate. Predator playbacks (wolf, dog, human) reduced deer patch use and crop damage on wheat fields more than playbacks of control sounds (owl, goose, raven). Our results confirm findings from previous studies in wilderness areas, and demonstrate that broadcasting predator playbacks using ABRs may provide an effective tool to reduce crop damage at the scale and duration of our study.
\end{abstract}

\section{Introduction}

Wild ungulates can have strong effects on their environment, and in human-dominated landscapes this may lead to conflicts with human land use such as agriculture (Reimoser and Putman, 2014). Ungulate numbers and distribution are increasing across Europe (Apollonio et al., 2010b; Linnell et al., 2020; Thulin et al., 2015) due to better conservation practices, wildlife management actions and increased availability of forage arising from agriculture and forestry practices (Ferretti and Lovari, 2014; Presley et al., 2019). Across Europe, these increasing populations lead to increased crop damage, affecting production and incomes in agriculture (Reimoser and Putman, 2014). Estimating the cost of wild ungulate grazing on agriculture is difficult because many countries lack national monitoring programs (Linnell et al., 2020; Reimoser and Putman, 2014). However, compensation for crop damage by wildlife represents $35 \%$ of the total global agricultural compensation (Ravenelle and Nyhus, 2017) and in some European countries reaches up to 13 million euro annually (Linnell et al., 2020). Agricultural impacts of ungulates, such as wild boar (Sus scrofa), fallow deer (Dama dama) and red deer (Cervus elaphus) are thus seen as an increasing problem (e.g. Apollonio et al., 2010a; Bleier et al., 2017; Marchiori et al., 2012; Menichetti et al., 2019; Schley and Roper, 2003).

Although expanding ungulate populations in Europe lead to increasing conflicts with human land use, they also play crucial roles in the functioning of Europe's ecosystems (Linnell et al., 2020). In fact, many stakeholders celebrate the ungulate comeback in Europe and

\footnotetext{
* Corresponding author.

E-mail address: anna.widen@slu.se (A. Widén).

1 This research was a collaboration between the labs of the Principal investigators, Cromsigt and Zanette.
} 
emphasize diverse positive impacts of increased ungulate populations (e.g. prey for large carnivores, carrion for scavengers and ecosystem engineers) and as a resource for hunters or wildlife tourism (see Linnell et al., 2020 for a detailed review). Managers thus face the challenge of maintaining and/or promoting these perceived positive values of increased ungulate populations while minimizing their negative impacts. Hence, while population control may in some cases be an efficient management tool to reduce crop damage (Geisser and Reyer, 2004) this may also counteract other management goals aimed at improving hunting, recreational value or conservation. There is thus an urgent need for management approaches that create/aim for variable ungulate densities across the landscape (low in conflict-prone areas, high in natural habitats or where focus is on wildlife use). One such management approach, which is receiving increasing interest, is the use of tools and methods to induce fear (anti-predator responses) to steer the behavior and distribution of wildlife across the landscape (Cromsigt et al., 2013; Garvey et al., 2020; Gaynor et al., 2020). In addition to creating variable densities across landscapes, this approach is also of interest for species that are difficult to control numerically (e.g., wild boar) and because society is increasingly asking for non-lethal tools to reduce conflicts (Blumstein, 2016; Cromsigt et al., 2013; Garvey et al., 2020; Gaynor et al., 2020; Reimoser and Putman, 2014; Shivik, 2006).

The science behind using fear as a tool to influence behavior is based on the so-called "ecology of fear" (Brown et al., 1999). The 'ecology of fear' posits that anti-predator behavior is powerful enough to have population-, community- and ecosystem-level impacts (Brown et al., 1999; Lima and Dill, 1990; McNamara and Houston, 1992), as corroborated in a growing number of experiments on free-living wildlife (reviewed in Zanette and Clinchy, 2020). Prey should respond strongly and consistently to the perceived presence of predators (Smith et al., 2017; Zanette and Clinchy, 2020), because the cost of failing to avoid a predator is almost certain death (Lima and Dill, 1990; Bouskila and Blumstein, 1992; Johnson et al., 2013). Consequently, compared to deterrents (e.g. scare crows or lines of flags along fence lines; Shivik, 2006) that do not simulate predator cues using fear as a tool in wildlife management may be more effective (Cromsigt et al., 2013; Garvey et al., 2020; Gaynor et al., 2020; Zanette and Clinchy, 2020). Animals may perceive the presence of predators using visual, olfactory and/or auditory signals (Creel and Christianson, 2008) and respond by either leaving or avoiding the risky area or increasing their vigilance, resulting in reduced time spent foraging (Brown et al., 1999; Lima and Dill, 1990; Kuijper et al., 2014; Gaynor et al., 2020; Zanette and Clinchy, 2020). Broadcasting auditory predator cues has proven to be a particularly effective means of inducing fear responses in wildlife (e.g. Zanette et al., 2011; Hettena et al., 2014; Suraci et al., 2016; Smith et al., 2017; Suraci et al., 2019b).

To develop effective acoustic tools that manipulate fear, one needs to know what auditory cues lead to the strongest anti-predator responses (Garvey et al., 2020; Gaynor et al., 2020; Smith et al., 2020). Prey may perceive and respond to different predators in very different ways due to differences in their vulnerability and/or their anti-predator strategies (Clinchy et al., 2016; Durant, 2000; Zanette and Clinchy, 2020; van Beeck Calkoen et al., 2021; Epperly et al., 2021). Recent worldwide analyses, however, have established that humans may be "super predators" (Darimont et al., 2015; Zanette and Clinchy, 2020) eliciting similarly strong antipredator responses in a wide range of ungulate and carnivore species (Zanette and Clinchy, 2020). Correspondingly, multiple recent predator playback experiments have demonstrated that ungulates and carnivores in Europe, Africa and North America fear hearing the human 'super predator' far more than non-human predators (Clinchy et al., 2016; Suraci et al., 2019b; Zanette and Clinchy, 2020).

The effective use of fear as a tool in wildlife management depends on minimizing habituation (Shivik, 2006; Blumstein, 2016; Zanette and Clinchy, 2020). Habituation is governed in part by the time between exposures to an aversive stimulus; irregularity and infrequency lessen the likelihood of habituation (Blumstein, 2016; Zanette and Clinchy,
2020). One should thus be able to minimize habituation by maximizing variation in the characteristics of the aversive stimulus and ensuring exposure is intermittent rather than continuous (Zanette et al., 2011; Garvey et al., 2020; Shivik, 2006). The Automated Behavioral Response system (ABR) represents a newly-developed tool that could be used in an applied setting to implement auditory fear cues while minimizing the chance of habituation at the scale of weeks (e.g. 4 weeks, Suraci et al., 2016; 5 weeks, Suraci et al., 2019b) and even entire breeding/growing seasons (e.g. 4 months, Zanette et al., 2011). This integrated camera trap - speaker system only broadcasts a sound when animal movement activates the camera sensor, thereby ensuring exposure is intermittent. The $\mathrm{ABR}$ can moreover be programmed to broadcast any sound in any order, ensuring variation is maximized, thereby further ensuring habituation is avoided (Suraci et al., 2017; Smith et al., 2020).

Systems, such as the ABR, may offer novel ways of applying the ecology of fear to mitigate human-wildlife conflicts. However, most studies using ABRs or similar systems have focused on changes in animal behavior and have not measured the consequences of these behavioral changes on the wildlife's landscape use and forage resources. Moreover, few have performed studies in the actual management setting where human-wildlife conflicts occur (Smith et al., 2020) but see (Thuppil and Coss, 2016) for the use of playbacks to reduce crop raiding by elephants (Elephas maximus) in India. A recent review of the use of frightening devices to protect crops found no examples of the broadcast of predator vocalizations as a measure to protect crops (Enos et al., 2021). Hence, we urgently need more studies that experimentally test these fear-manipulating tools, such as ABRs, in an actual management context and link behavioral responses to the ungulate impacts on the landscape, such as crop damage. In this study, we used ABRs to broadcast predator vocalizations, and thus manipulate fear, to test whether inducing fear can reduce crop damage. In addition, we had two sets of ABRs programmed with different frequencies at which predator and control vocalizations were triggered; a set of ABRs with high frequency of predator playbacks ("high-predator level") and a set of ABRs with lower frequency of predator playbacks ("low-predator level"). We then compared patch use by ungulates and crop damage between regular camera traps sites (no-sound controls), "high-predator level" ABR sites and "low-predator level" ABR sites.

\section{Methods}

\subsection{Study area description}

The study was performed in the county of Södermanland, in the hemiboreal climate zone of southern Sweden $(58.963899$ N, 17.156465 E, Fig. 1a). The climate is mild with a monthly mean temperature of 16-20 degrees in May-July and mean precipitation of 75-100 mm, (Swedish Meteorological and Hydrological Institute (SMHI), 2021). A mosaic of boreal forests and agriculture characterizes the county with $20-39 \%$ of the total land area being used as agricultural land (Jordbruksverket, 2020a). The agricultural land comprises a mixture of crops with cereals (wheat, barley and oat being the three dominant species), grass (leys) and rape seed (canola) (Brassica napus) being the three most common crops (Jordbruksverket, 2020b). The average annual yields in the county are $7240 \mathrm{~kg} / \mathrm{ha}$ (winter wheat), $4230 \mathrm{~kg} / \mathrm{ha}$ (barley), 4510 $\mathrm{kg} / \mathrm{ha}$ (oat), $2680 \mathrm{~kg} / \mathrm{ha}$ (grass) and $3470 \mathrm{~kg} / \mathrm{ha}$ (rape seed) (Jordbruksverket, 2020c). In addition to crop fields, the area consists of cattle farms and a relatively large number of estates that obtain income from selling hunting rights on several wild ungulate species. These estates maintain high densities of ungulates through supplementary feeding during winter and other forms of wildlife habitat management (e.g., sowing game crops). This diversity in land use is creating conflict in the area, where farmers are increasingly concerned about crop damage by the high-density populations of wild ungulates. Moose (Alces alces), roe deer (Capreolus capreolus), red deer (Cervus elaphus), fallow deer (Dama dama) and wild boar (Sus scrofa) coexist in the study area. The 

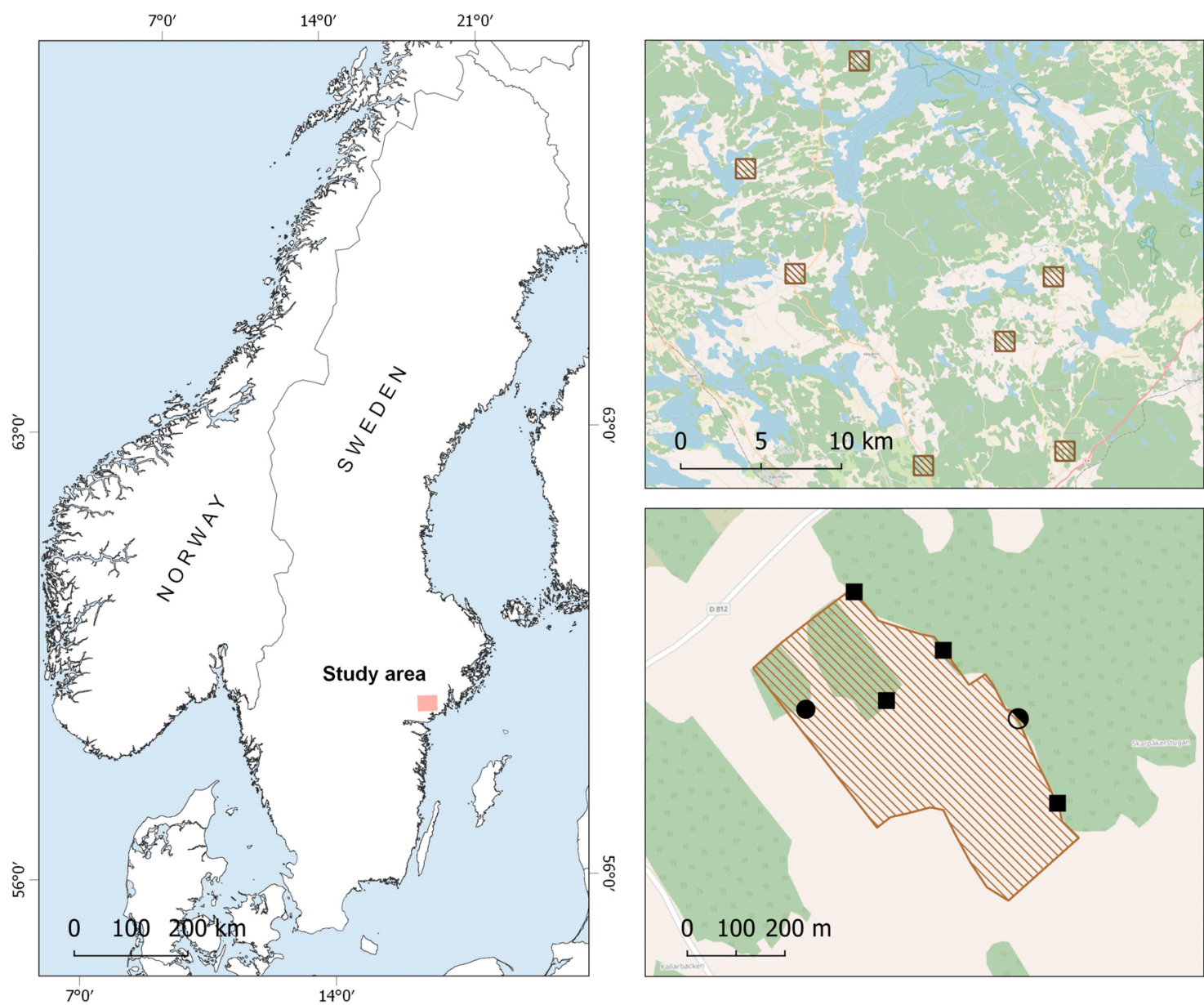

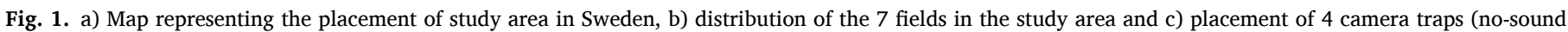
controls) and ABRs on one example field. (For color please see online figure)

populations of these ungulates are managed through regulated annual hunting. The main form of hunting is with baying dogs, but sit and wait hunting and stalking occur as well. Hunting is seasonal for the deer species, but is allowed year-round for wild boar. However, baying dogs cannot be used during February-July. During the hunting season $2019 / 2020$, ungulates were harvested at the following rates within the hunting district, indicative of their relative abundances: $\sim 69$ fallow deer per 1000 ha, $\sim 14$ wild boar per 1000 ha, $\sim 2$ Moose per 1000 ha, $\sim 5$ roe deer per 1000 ha and $\sim 2$ red deer per 1000 ha and (moose data: (Länsstyrelserna, 2021) other ungulates: (Svenska Jägareförbundet, 2021)).

Wolves were absent in the study area and locally extinct since the late 19th century (Ekman, 2010). However, during recent years, observations of single wolves have increased in the area and since 2015 a wolf pack established a territory in the area with 1 confirmed reproduction in 2021. Lynx occur sporadically in the area, but no permanent family groups have been confirmed to date.

\subsection{Experimental design}

Within our study area, we selected seven independent crop fields (Fig. 1b), ranging between 15 and 28 ha in size, sown with winter wheat (Triticum aestivum). We selected fields that were at least $4 \mathrm{~km}$ apart, which reflects the average home range size of fallow deer (Borkowski and Pudelko, 2007; Ciuti et al., 2003; Davini et al., 2004). Fallow deer is the most common ungulate in the study area (see above) and responsible for a considerable proportion of the crop damage in the region (personal communication with local landowners). By keeping the $4 \mathrm{~km}$ distance, we assumed that our fields were visited by different fallow deer herds. Furthermore, the fields were situated next to country roads, except for one, which was $100 \mathrm{~m}$ away from a larger road. Distance to settlements and housing ranged from $100 \mathrm{~m}$ to $284 \mathrm{~m}$ with an exception of one field having a settlement $50 \mathrm{~m}$ from the field edge. All fields had at least one field edge covered by forest.

We experimentally broadcasted predator vocalizations with the objective of increasing perceived predation risk in certain locations of our crop fields. Instead of continuously broadcasting sounds, we used Automated Behavioral Response systems (ABRs) (Suraci et al., 2017), consisting of a video-enabled camera trap (BTC-8FHD-PX; Browning Trail Cameras, Morgan, UT) linked to a playback speaker unit triggered by the camera's activation. The CT activates the speaker unit as soon as a passing animal triggers the passive infrared sensor of the camera. Before the start of the experiment, we searched for locations which were intensively used by ungulates along the edges of all fields (e.g., well-used game trails coming out of the forest into the field, high abundance of dung or tracks). We then confirmed this initial assessment by deploying four camera traps capturing images (HC500; Reconyx Inc., Holmen, WI; from here on referred to as "regular CTs") in the identified spots per field (two fields had five camera traps). We ran those CTs for one week starting 4th of June 2020. Based on this information, we then placed CTs and ABRs on the most highly used parts of each field's forest edges for a six-week long study (Fig. 2). During the first two weeks, we disabled the sound system of the ABRs to allow us to record "pre-playback treatment" differences in ungulate patch use in front of regular CTs and ABRs and contrast ungulate patch use between pre-treatment and during treatment. During these first two pre-treatment weeks, each field thus had six 


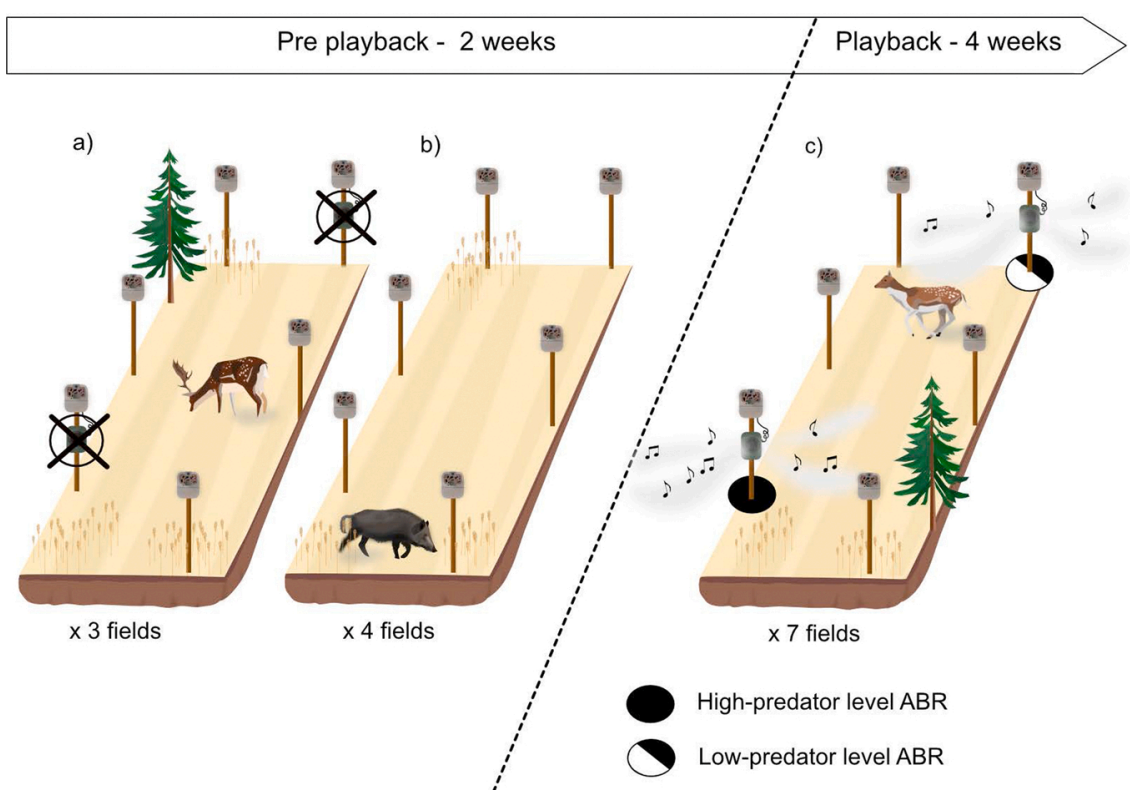

Fig. 2. Explanation of the different study phases and study design. a) Three fields were deployed with 4 camera traps (regular CTs) and 2 ABRs with disabled sound systems during the pre-playback period. B) 4 fields were deployed with 6 regular CTs ( 2 of them on ABR locations) during the pre-playback period. C) During the playback period, all 7 fields were deployed with 4 regular CTs and 2 ABRs, one with high frequency of predator vocalizations (high-predator level) and one with low frequency of predator vocalizations (low-predator level). During these playback weeks, ABRs and CTs were placed on the exact same spots as during the pre-playback weeks. (For color please see online figure) cameras, where on four fields these were all regular CTs and on three fields two were ABRs and four were regular CTs. ABRs and regular CTs used different camera trap models (Browning vs. Reconyx) and ABRs recorded videos whereas regular CTs captured images. We used the pre-treatment data to test if this led to detection differences between ABRs and regular CTs.

During the next four weeks, starting June 29 2020, we started the actual playback experiment and placed ABRs on all seven fields at the same locations with activated playback systems. Each field had four CTs and two ABRs at the same locations as we used during the first two weeks (Fig. 2c). During this playback experiment, we broadcasted predator (dog, wolf, human) and non-predator control vocalizations (goose, owl, raven, see below for more details). We refer to the locations of the two ABRs in each field as "experimental plots" whereas the regular CTs in each field served as "no-sound control plots". On each field, the two ABRs were deployed at least $400 \mathrm{~m}$ from each other to ensure that the playbacks broadcasted at one ABR location were not audible at the other. In the field, we could no longer hear the ABRs at a distance of $\sim 150 \mathrm{~m}$, however, as ungulates have better hearing than humans, we decided to place ABRs at least $400 \mathrm{~m}$ apart. We also aimed for at least $200 \mathrm{~m}$ distance between regular CTs and ABRs, and between regular CTs. On four fields this distance was not possible due to the size of fields and other practical restrictions such as keeping the surrounding habitat similar. In these cases, the distance between regular CTs (the ones without sound playbacks) were a minimum of $100 \mathrm{~m}$. We placed ABRs and regular CTs on $1.5 \mathrm{~m}$ high poles, facing a parallel direction along the forest edge. The poles were placed on the field edge in immediate connection to the planted crop and thus also adjacent to the forest edge.

\subsection{ABR settings}

When an animal triggered the ABR camera's sensor, the camera started recording a video and the attached speaker started broadcasting a playback from unique pre-determined playlists (see Supplementary Materials for the playlists). These playlists were made up of the vocalizations of different predator and non-predator control (bird) playback types (Hettena et al., 2014; Crawford et al., 2022; Epperly et al., 2021). All of the species whose vocalizations we used were naturally occurring in our study area. The predator vocalizations comprised of dogs (barking), wolves (barking and howling) and humans (talking). As controls, we used the vocalizations of different bird species, similar to previous ABR experiments on the fear responses of ungulates (Crawford et al.,
2022; Epperly et al., 2021). In our experiment, we used Barnacle goose (Branta leucopsis), Common raven (Corvux corax) and Tawny owl (Strix aluco), which are all common in our study area and have comparable sound characteristics (e.g. pitch and interval) to those of the predators. By choosing non-predator control vocalizations with similar sound characteristics to the predator vocalizations, we aimed to ensure that any difference in response to predator vocalizations was attributable to perceived predation risk, and not to differences in sound characteristics (e.g. lower vs. higher pitch; Zanette et al., 2011; Hettena et al., 2014; Suraci et al., 2016; Zanette and Clinchy, 2020). We broadcasted different bird species according to the appropriate times in the diel cycle (i.e., goose and raven during the day, owl at night). Note that the species of birds used were not of interest to the study. The objective was to compose a single class of vocalizations, i.e. controls, and hence, as in previous ABR experiments, no analyses were conducted of differences in responses to the different birds.

We used 10 exemplars of each playback type (i.e., species vocalization). The 10 human exemplars consisted of recordings of ten different individuals, 5 females and 5 males, speaking conversationally in Swedish (i.e., reading different texts in a neutral fashion not conveying alarm or threat; following Clinchy et al., 2016; Smith et al., 2017; Suraci et al., 2019a, 2019b; Crawford et al., 2022). Sound files of dogs and wolves originated from online audio and video databases, and library archives, and bird playbacks were downloaded from https://www.xenocanto.org. Dog exemplars included recordings of multiple breeds, e.g. Alsatians, Dobermans and hunting hounds. We edited all sound files for consistency in amplitude and quality using Audacity ${ }^{\circledR}$ (www.audacityt eam.org) and broadcasted the playbacks at a consistent mean sound pressure level of $80 \mathrm{~dB}$ at $1 \mathrm{~m}$, to ensure responses to the playbacks were unrelated to variability in sound intensity across or within treatments and loud enough to be audible within the $15 \mathrm{~m}$ detection range of the camera's motion sensor (Smith et al., 2017; Suraci et al., 2019b; Zanette and Clinchy, 2020; Crawford et al., 2022; Epperly et al., 2021).

Each playlist consisted of $24 \mathrm{~h}$ divided into 15-minute intervals, each of which contained one playback type (i.e., one species vocalization). We pre-determined the order of playback types in each playlist, balancing and randomizing predator and control playback types across the $24 \mathrm{~h}$ and avoiding order effects. In the end, we had 4 different playlists (two for the High-predator, and 2 for the Low-predator treatment, see further below), which were used in our ABRs (please see the Supplementary Materials for each playlist). This set-up follows an established protocol from previous ABR experiments (see Crawford 
et al., 2022 for a detailed explanation of the reasoning behind this set-up). The set-up determines that the playback type changed every 15 min (if camera was triggered), broadcasting randomly-selected exemplars from that playback type within the $15 \mathrm{~min}$, but switching to a different playback type for the next 15-minute interval (if the camera was triggered). To illustrate this, if an animal triggered the ABR between, e.g., 12:00 and 12:15, the speaker would select a playback from the pre-determined playlist, e.g. Tawny owl, and start playing a random exemplar of Tawny owl. If the animal remained in the vicinity and re-triggered the ABR within this interval, the ABR would broadcast a different, randomly selected, exemplar of Tawny owl. If the animal left the vicinity and returned during the next 15 min interval, 12:15 and 12:30 (or a later time), the ABR would broadcast a different playback type, e.g. humans.

When programming the ABRs, we also needed to set the delay and the duration of the playback vocalization (Suraci et al., 2017). To ensure that one captures the response of the animal to the broadcast vocalization, one needs to select a delay between the start of the video recording and the start of the sound broadcasting so that the animal is in full view in the video when the broadcast starts. If this delay is too short, then the video may not capture the immediate response of the animal to the sound, if the delay is too long, the animal may be out of sight. The optimal delay varies among species and systems (Suraci et al., 2017). We, therefore, determined the optimal delay through a separate two-week trial (starting 9th June 2020) with six ABRs deployed in a fallow deer enclosure and on grass fields. Based on this trial, we set the system such that the playback started three seconds after the camera was triggered. Following a well-established protocol used in previous ABR experiments, we set the duration of all different playback types to $10 \mathrm{~s}$ and set the camera to record 30 second videos (Crawford et al., 2022; Epperly et al., 2021). Hence, during each $30 \mathrm{~s}$ video, there was $3 \mathrm{~s}$ of silence, followed by $10 \mathrm{~s}$ of the playback sound and then another $17 \mathrm{~s}$ of silence (Crawford et al., 2022).

\subsubsection{ABR Programs "high-predator level" and "low-predator level"}

In addition to comparing the patch use and crop damage between ABR locations and no-sound control locations (regular CTs), we compared ungulate visitation between the two ABRs on each field, which were programmed to broadcast predator vocalizations at two different intensities; one ABR being programmed with the aim of inducing a high level of predator-induced fear and the other a low level. The low-predator level ABRs were programmed such that, during each 2-hour period, there were five 15-min intervals during which animals would hear controls (birds) if the ABR was triggered, one 15-min interval during which they would hear dogs, one during which they would hear wolves and one during which they would hear humans. The highpredator level ABRs were programmed such that, during each 2-hour period, there were two 15-min intervals during which animals would hear controls (birds) if the ABR was triggered, two 15-min intervals during which they would hear dogs, two during which they would hear wolves and two during which they would hear humans. Hence, during any given 2-hour period animals would be twice as likely to hear predator vocalizations when passing by high-predator level ABRs compared to when passing low-predator level ABRs (Crawford et al., 2022).

\subsection{Crop damage measurements}

We measured crop damage by ungulates on the fields at the end of the playback experiment, starting the 1st of August 2020, using two $25 \mathrm{~m}$ long transects starting at the location of each ABR and regular CT unit (Fig. 3). To cover a larger area in front of the ABR and regular CT one transect faced the same direction as the ABR and regular CT, and the other one faced 45 degrees away from the direction the ABR/regular CT were facing. On each transect, we laid out $1 \mathrm{~m}^{2}$ square plots at $5,10,15$, 20 and $25 \mathrm{~m}$ distances along the transect. In each of these plots, we

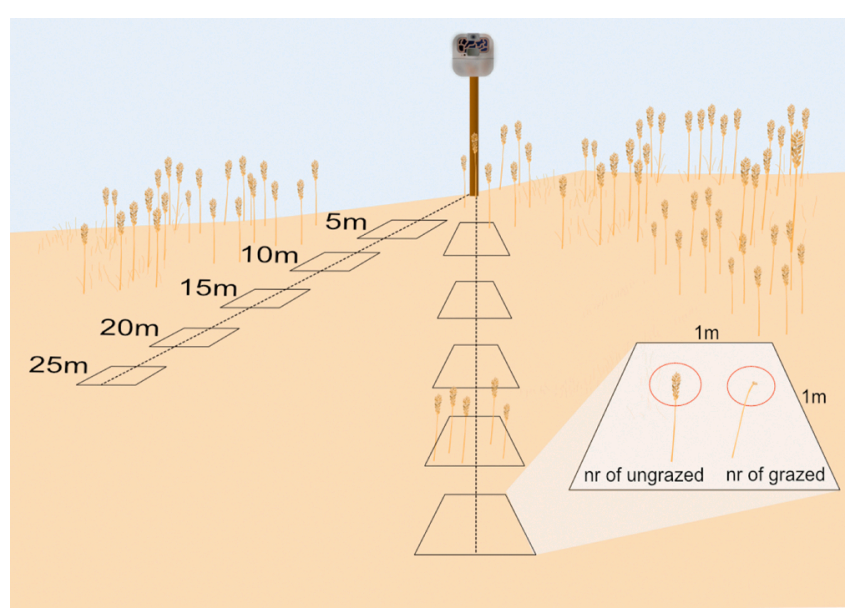

Fig. 3. Outline of crop damage measurements. Crop damage was measured along two transects of $25 \mathrm{~m}$, one facing in the same direction as the camera trap/ABR and the other one in a 45 degree angle. Along the transects, $51 \mathrm{~m} 2$ square plots were distributed in which the number of grazed and ungrazed wheat straws were counted. (For color please see online figure)

determined damage as the proportion of wheat stalks where the top culm had been entirely or partly grazed, relative to all stalks in the plot (Fig. 3). We thus ended up with 10 crop damage measurements per ABR or regular CT unit, leading to 60 crop damage measurements per field.

\subsection{Processing of camera trap data}

Images from regular CTs and videos from ABRs of fallow deer, red deer, roe deer, moose and wild boar were identified and classified in the camera trap data management platform TRAPPER (Bubnicki et al., 2016). Before classification, sequences with $5 \mathrm{~min}$ interval were generated (following Bubnicki et al., 2019), where photos/videos that were captured within $5 \mathrm{~min}$ from each other belonged to the same sequence, i.e. one sequence could consist of a visit of a single individual or group of individuals. We recorded the species present in that sequence and the maximum number of individuals per species on a photo/video in that sequence and we converted the camera trap data into a measure of patch use by multiplying the length of each sequence in seconds (as the difference between start time and end time of a sequence) with the maximum number of individuals in the sequence. In this study, we were ultimately interested in testing if broadcasting risk cues can reduce crop damage. Because of this crop damage perspective, our main analysis did not focus on changes in ungulate individual behavior, but on changes in the overall use of, or pressure on, the plot by ungulates (i.e., independent of whether this use was by the same individual or different individuals).

As explained in the Introduction, animals should leave areas they perceive as fearful; and leave more rapidly the greater the perceived fear (e.g. when more frightening predators are heard; Brown et al., 1999; Zanette and Clinchy, 2020). Correspondingly, the rate at which animals leave or return to a food patch has been used to estimate the relative fearfulness of different predator vocalizations in most previous $A B R$ experiments (Smith et al., 2017; Suraci et al., 2019b; Crawford et al., 2022). Accordingly, we quantified the relative fearfulness of the different playback treatments in our experiments based on 'total bout duration', defined as follows. Adhering to an established protocol from previous ABR experiments (Crawford et al., 2022; Epperly et al., 2021), we categorized videos into independent treatment-specific bouts if $>60$ min elapsed since the last time the same species heard the same sound treatment at that site. The first video of a given species at a given site hearing a given treatment, if either, there were no prior exposures to that treatment, or $>60 \mathrm{~min}$ had elapsed since the last exposure to that treatment, we term a 'first' exposure video. If the vocalization heard is not frightening (e.g. birds), the animal may remain and feed on the crop, 
in which case it would re-trigger the $\mathrm{ABR}$ within the same $15 \mathrm{~min}$ interval, and hear the same playback type (e.g. birds), Videos of the same species at the same site, hearing the same treatment $<60$ min since the last time they did, cannot be considered independent and we term these 'repeat' exposure videos. An independent treatment-specific 'bout' thus comprises a 'first' video and any and all 'repeat' videos. The 'total bout duration' is the sum of the intervals between the first exposure video and all subsequent repeat exposure videos in a bout. If there was just one video, i.e., just one first exposure alone, as is likely when the vocalization heard is very frightening and the animals flee the vicinity, the total bout duration is $30 \mathrm{ss}$ (the length of the video).

\subsection{Statistical analysis}

All analyses on patch use were carried out in R 4.0.0 (R Core Team, 2013). To test for a possible detection difference between the different camera models and recording types (video vs image) of the ABRs and regular CTs, we compared patch use between ABRs and regular CTs using the data from pre-playback weeks with a Linear mixed effect model (LMM). Here we compared three fields, since we only had ABRs on three fields during this initial pre-treatment trial. In this model, the response variable was patch use and fixed factor was camera type with two levels (regular CTs vs ABRs), field ID was added as random intercept.

\subsubsection{Patch use and crop damage}

All analyses on patch use were carried out using LMM with a Gaussian error distribution or generalized linear mixed effect models (GLMM) with a Binomial error distribution as implemented in the lme4 package (Bates et al., 2015). When modeling patch use, we included the $\log 10$ transformed number of days the camera/ABR had been out in the field as an offset, to correct for differences in camera functioning. Furthermore, we added Field ID as a random intercept to correct for potential dependence of patch use estimates within fields. When modeling crop damage, we added a random intercept for each transect nested within location nested within field ID to correct for the hierarchical structure of the crop damage measurements.

We performed several analyses to look at differences in patch use between the CTs and the two ABR programs. We performed these analyses on the patch use of the combined patch use of all ungulate species and of each species separately, for the species with sufficiently high sample size.

We first ran a LMM to compare patch use between the pre-treatment weeks and the treatment weeks. Here, we grouped the two ABR programs (High-predator level and low-predator level) per field to test if the patch use was lower in front of ABRs than in front of regular CTs during the playback treatment weeks. Here, patch use index was log transformed. Treatment with two levels (regular CT versus ABR) and Period with two levels (before versus during playback treatment) were included as fixed effects. We included the interaction between treatment and period to test whether the difference in visitation in front of regular CTs versus ABRs depended on the playback treatment being active or not.

To test how patch use varied among the three overall sound treatments (regular CTs as no-sound treatment, high-predator level ABR and low-predator-level ABR), we fitted LMM for only the treatment weeks. The response variable in this model was again patch use, which was log transformed. Camera type was included as a fixed factor with three levels (no-sound control CT, Low-predator level ABR and High-predator level ABR).

Finally, we tested if crop damage on fields varied among the plots with regular CTs, high-predator level ABRs and low-predator-level ABRs using a GLMM. In this model, the response variable was the proportion of damaged wheat straws within each $1-\mathrm{m}^{2}$ measuring plot and camera type was again included as a fixed factor with three levels (no-sound control CT, high-predator level ABR and low-predator level ABR).

\subsubsection{Total bout duration}

To test whether there was a difference in total bout duration among the four vocalization treatments (bird control, dog, wolf, human) we conducted a GLMM with zero truncated negative binomial distribution using the glmmTMB package. We added ABR ID nested within Field ID as a random intercept to account for the hierarchical structure of the bout duration measurements.

To test whether there was a difference in predator vocalization videos between the high-predator level ABR and the low-predator level $\mathrm{ABR}$, we conducted Wilcoxon Matched Pairs tests, comparing predator vocalization videos in total, and dog, wolf and human vocalization videos considered separately.

\section{Results}

Average trapping rates (number of sequences/number of regular CTs/ABRs) and coefficient of variation across all locations used in the study were $14.6(\mathrm{CV}=0.79)$ for fallow deer (no-sound control $=17.1$, $\mathrm{CV}=0.75$; low-predator level $=9.6, \mathrm{CV}=0.62$; high-predator lev$\mathrm{el}=8.6, \mathrm{CV}=0.67), 14.5(\mathrm{CV}=1.14)$ for roe deer (no-sound control $=18.6, \mathrm{CV}=0.97$; low-predator level $=6.2, \mathrm{CV}=1.39$; highpredator level $=4.5, \mathrm{CV}=0.78), 5.25(\mathrm{CV}=1.45)$ for red deer (nosound control $=5.1, \mathrm{CV}=1.54$; low-predator level $=8, \mathrm{CV}=0$; highpredator level $=2.5, \mathrm{CV}=0.28), 4.07(\mathrm{CV}=1.35)$ for moose (nosound control $=4.5, \mathrm{CV}=1.36$; low-predator level $=2, \mathrm{CV}=0.7$; highpredator level $=3, \mathrm{CV}=0), 4.9(\mathrm{CV}=0.93)$ for wild boar (no-sound control $=5.2, \mathrm{CV}=0.93$; low- predator level $=7, \mathrm{CV}=0.60$; highpredator level $=2, \mathrm{CV}=0$ ), and Overall ungulate patch use did not significantly differ between ABRs and regular CTs during the pretreatment trial, when ABRs were not broadcasting sounds (F-value: 0.71, p-value: 0.41 ).

The total number of videos recorded at the two differently programmed ABRs were 166 at high-predator level ABR (predator vocalization videos $=129$, control vocalization videos $=37$ ) and 289 at lowpredator level ABR (predator vocalization videos $=98$, control vocalization videos $=191$ ).

\subsection{Patch use and crop damage}

\subsubsection{Differences in patch use before and during the playback treatment}

We found no difference in patch use between regular camera trap locations and ABR locations during the pre-treatment period (t-val$\mathrm{ue}=0.50, \mathrm{p}=0.618$ ) (Fig. 4), During treatment there was a significant difference in patch use between ABR locations and CT locations with higher patch use at CT locations ( $\mathrm{t}$-value $=3.05, \mathrm{p}=0.003$ ). Patch use increased at regular CT locations during treatment ( $\mathrm{t}$-value $=2.06$, $\mathrm{p}=0.04$ ) (Fig. 4), patch use at ABRs did not change significantly during treatment (t-value $=-0.57, \mathrm{p}=0.5$ ) (Fig. 4).

\subsubsection{Influence of different levels of predator-induced fear on patch use}

During the treatment weeks, patch use differed between the nosound controls, low-predator level ABRs and high-predator level ABRs (F-value $=3.47, \mathrm{p}=0.04$; Fig. 5). Patch use was lower at high-predator risk ABR locations compared to no-sound control locations (t-val$\mathrm{ue}=2.17, \mathrm{p}=0.03$ ) and at low-predator level ABRs compared with nosound controls, although this latter difference was only marginally significant ( $\mathrm{t}$-value $=-1.92, \mathrm{p}=0.07$ ). There was no difference in patch use between high-predator level and low-predator level ABRs (t-val$\mathrm{ue}=0.31, \mathrm{p}=0.76$; Fig. 5). Notably, although the high-predator ABRs were programmed to broadcast predator vocalizations at a higher intensity, the actual number of predator vocalization videos recorded at high-predator ABRs was not substantially greater than at low-predator ABRs (129 vs. 98 respectively), and the difference was not statistically significant (Wilcoxon Matched Pairs tests, all $\mathrm{p}>0.500$ ).

Patch use of red deer, moose and wild boar could not be analyzed separately due to low sample sizes for these species. Patch use of fallow 


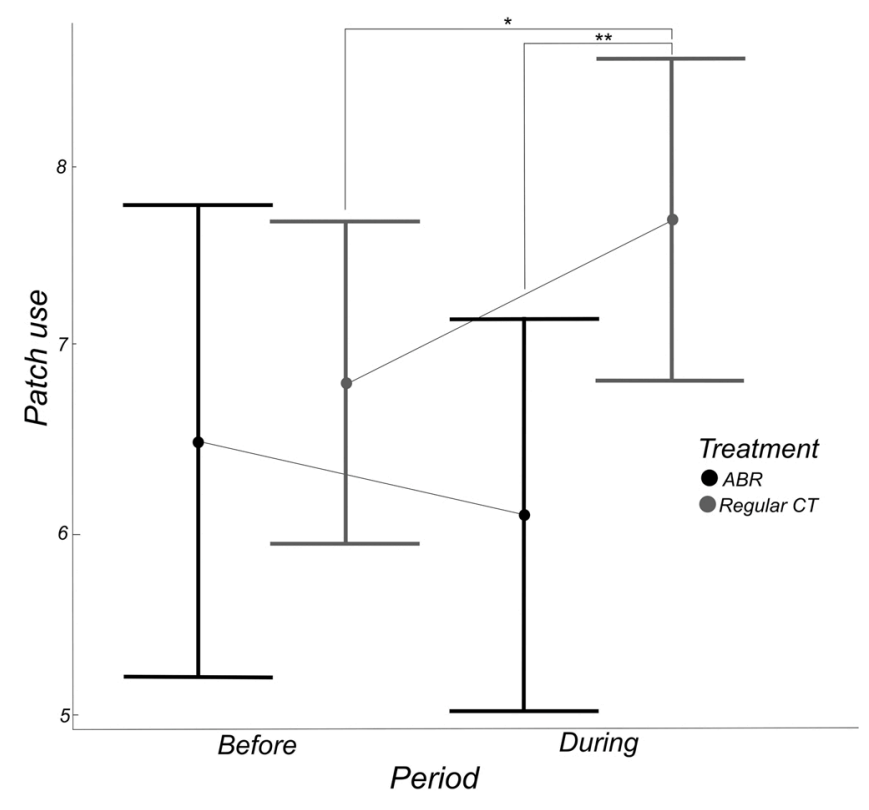

Fig. 4. Model prediction plot from a linear mixed effect model showing the difference in patch use (log transformed) between the two treatments ABR and regular CTs as well as between the two periods before manipulation of predator vocalizations and during manipulation of predator vocalizations. Bars represent predictions $+95 \%$ confidence interval. * denotes significant differences between the treatments.

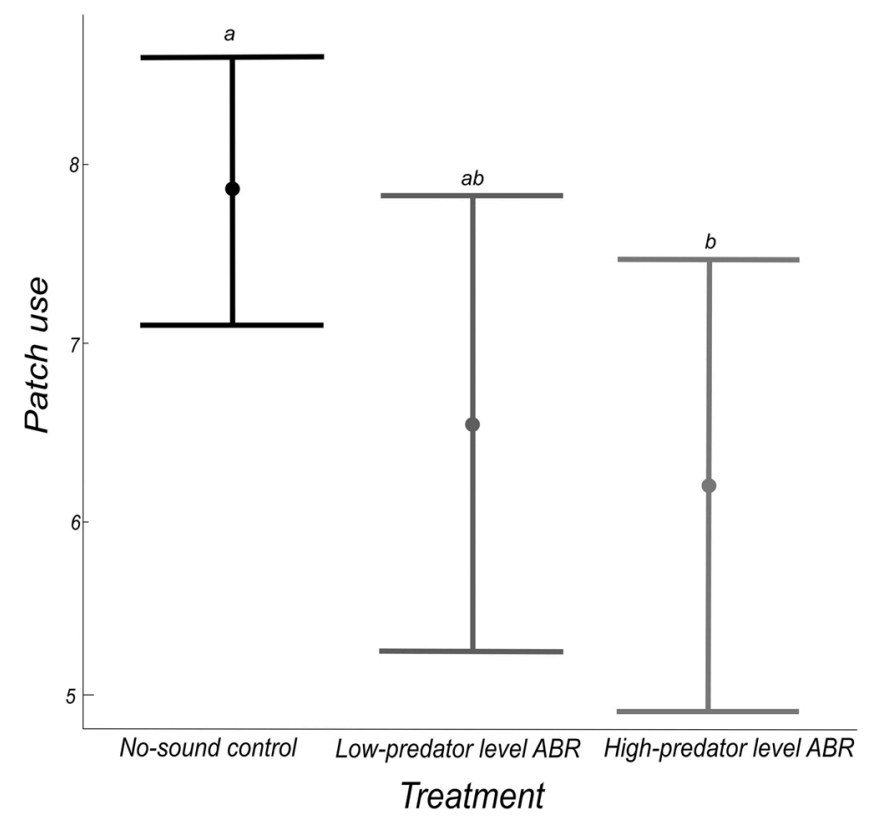

Fig. 5. Model prediction plot from a linear mixed effect model showing the difference in patch use (log transformed) between the three treatments during manipulation of predator vocalizations; no-sound control, low-predator level and high-predator level ABRs. Bars represent predictions $+95 \%$ confidence interval. Shared letters denote non-significant differences.

deer and roe deer differed among the three treatments (Fig. 6; fallow deer, $\mathrm{F}$-value $=3.25, \mathrm{p}=0.04 ;$ and roe deer, $\mathrm{F}$-value $=14.78$, $\mathrm{p}=<0.001$ ). Fallow deer patch use was lower at high-predator level than at no-sound control sites, (t-value $=-2.17, \mathrm{p}=0.03$ ), and tended to be lower in low-predator level ABRs than no-sound controls (t-val$\mathrm{ue}=-1.71, \mathrm{p}=0.09)$. Roe deer patch use was lower at both highpredator level (t-value $=-2.52 \mathrm{p}=0.01$ ) and low-predator level (t- value $=-5.19, \mathrm{p}=<0.001)$ ABR sites compared to the no-sound control sites. We did not find any difference in patch use between highpredator level and low-predator level ABRs for either fallow deer (tvalue $=0.56, \mathrm{p}=0.58)$ or roe deer ( $\mathrm{t}$-value $=-1.58, \mathrm{p}=0.13$ ).

3.1.3. Influence of different levels of predator-induced fear on crop damage Crop damage was lower at ABR locations than no-sound control locations (Chisq $=28.38$, pr $(>$ Chisq $)=<0.001)$. Furthermore, crop damage tended to be lower at high-predator level ABR sites compared to low-predator level ABR sites $(\mathrm{t}=1.76, \mathrm{p}=0.08)$ (Fig. 7).

\subsection{Total bout duration}

Total bout duration significantly differed among the vocalization treatments (control, dog, wolf, human) (Chisq $=49.559$, pr $(>$ Chisq $)=<0.001)$. Human vocalizations triggered the strongest responses (Fig. 8), where bout durations following human sounds were consistently shorter compared to durations following other vocalizations (human vs. control Z-value $=6.85, \mathrm{p}=<0.001$; human vs. $\operatorname{dog} \mathrm{Z}$ value $=4.61, \mathrm{p}=<0.001$; human vs. wolf $\mathrm{Z}$-value $=3.09, \mathrm{p}=0.002$ ). Compared to non-predator controls (Fig. 8), ungulates significantly reduced their bout duration in response to hearing wolves (Z-val$\mathrm{ue}=-3.18, \mathrm{p}=0.001$ ), and they tended to reduce their bout duration in response to hearing dogs $(\mathrm{Z}$-value $=-1.78, \mathrm{p}=0.075)$.

\section{Discussion}

Overall ungulate patch use and crop damage were much lower in plots in front of ABRs than in plots in front of regular CTs (no-sound control). Moreover, the difference between ABRs and no-sound control plots in patch use (Fig. 5) and crop damage (Fig. 7) was stronger for the high-predator level ABRs than for the low-predator-level ABRs. Our behavioral analysis of total bout duration confirmed that predator vocalizations induced stronger fear responses than non-predator vocalizations. Ungulates more quickly left a plot (shorter bout duration) after hearing predator vocalizations than after control bird vocalizations (Fig. 8). With regards to wildlife management, we demonstrate that experimentally broadcasting predator vocalizations, using systems such as ABRs, has potential as a tool to mitigate human-wildlife conflicts and can effectively reduce wildlife use and crop damage, at least at the scale, and for the duration, of our study.

Before we began broadcasting vocalizations (i.e. during the 2 weeks the ABRs were muted), there was no significant difference in patch use between ABR locations and regular camera trap locations (Fig. 4). Interestingly, during the playback treatment period, patch use increased in locations in front of the regular CTs (no-sound control), while it decreased at ABR locations (albeit not significantly so) (Fig. 4). This increase in patch use of the no-sound control locations might reflect an increase in overall field use due to a ripening of the crop and/or redistribution of the use within the field away from the ABRs towards the nosound control locations. Observational studies similarly found that fear may lead to a redistribution of prey moving to safer areas (Blumstein and Daniel, 1995; Creel et al., 2008; Creel and Winnie, 2005). Recently, Suraci et al. (2019b) experimentally demonstrated that mountain lions (Puma concolor) altered their movement and space use in response to hearing playbacks of the human 'super predator' speaking, broadcast using systems similar to the one we used here.

Although the high-predator ABRs were programmed to broadcast predator vocalizations twice as often (i.e., 100\% more) as the lowpredator ABRs, the actual number of videos with predator vocalizations recorded at high predator ABRs was only $32 \%$ greater than at lowpredator ABRs, most likely explaining the modest difference observed in patch use between the low-predator level and high-predator level. One possible explanation for this lies in the total bout duration results; i.e., animals left plots more quickly following a predator vocalization than following a control vocalization, so there are consequently fewer 


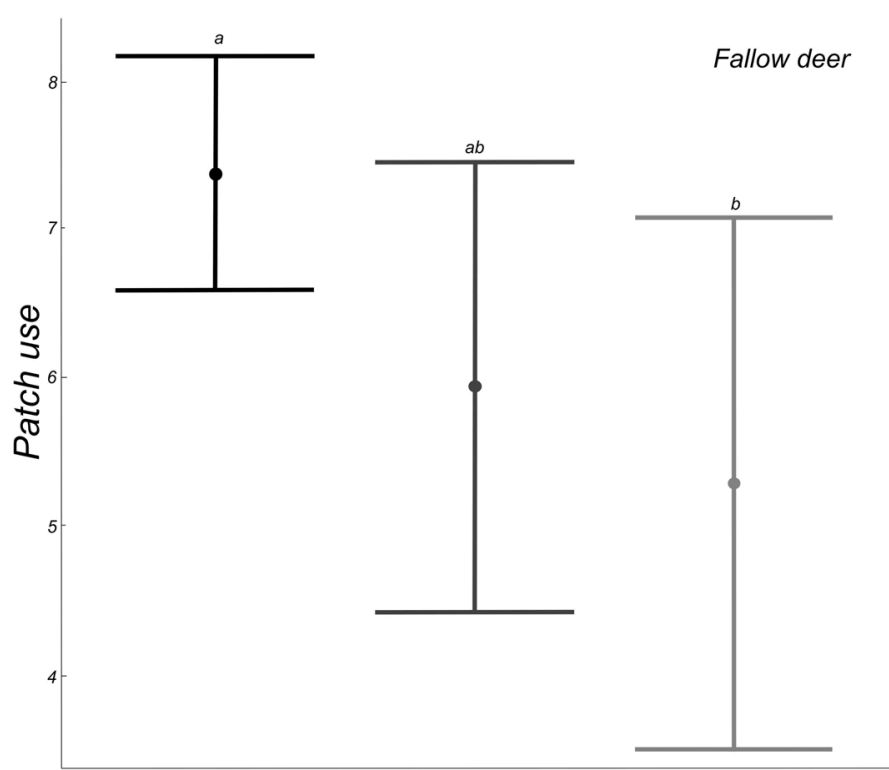

No-sound control Low-predator level ABR High-predator level ABR

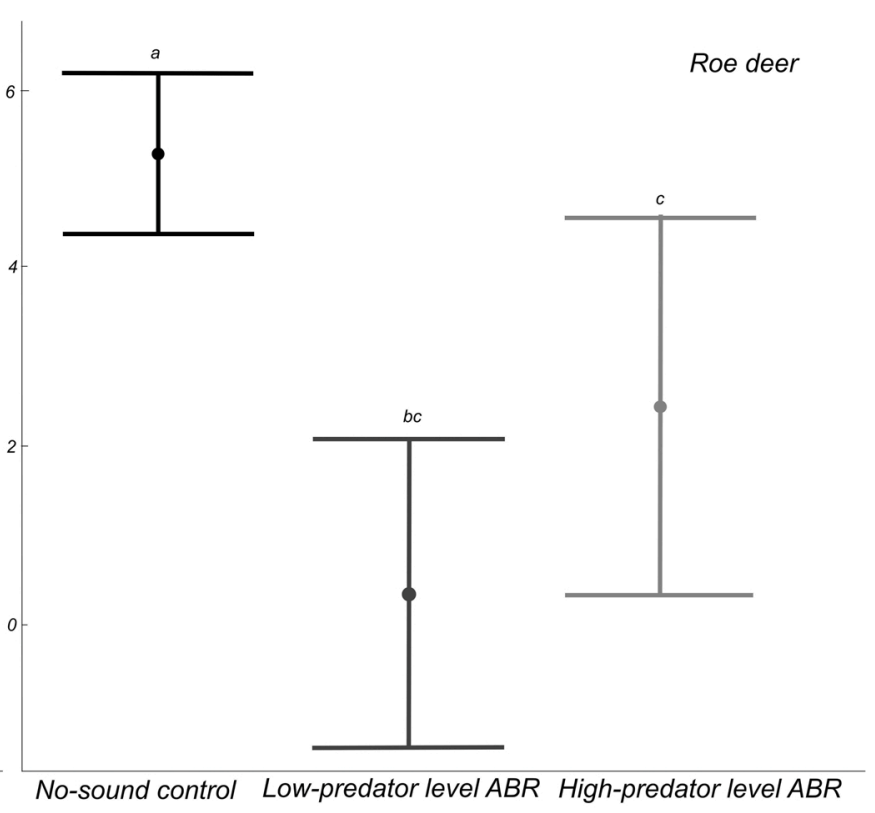

\section{Treatment}

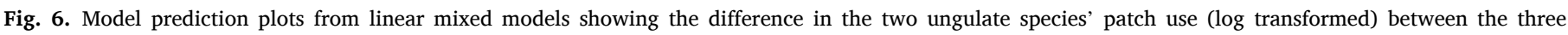

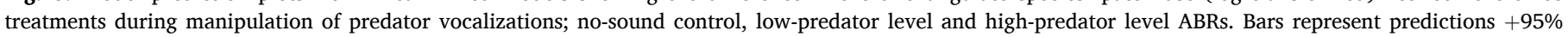
confidence interval. Shared letters denote non-significant differences.

'repeat' predator videos. The actual number of videos with predator vocalizations is thus a function of both how ungulates behave after hearing a vocalization and the difference in programming between the ABRs. The total bout duration results further demonstrate that which specific predators were heard can be expected to affect patch use, with patches being abandoned more when humans were heard (Fig. 8). This helps explain why patch use by roe deer was lower at low-predator level ABRs than high-predator ABRs (Fig. 6), because roe deer actually heard four times as many human vocalization playbacks at low-predator ABR locations than high-predator ABR locations.

The pattern of our total bout duration response to the four vocalization treatments (control, dog, wolf, human; Fig. 8) corresponded precisely with that from a prior predator playback experiment on deer in the southeastern USA (Crawford et al., 2022). I.e., that bout duration responses were strongest to human vocalizations, then to wolf vocalizations, and with only a weak response to dog vocalizations. This suggests that the effects on patch use and crop damage observed in our study were likely attributable to predator-induced fear. Our results confirm those from previous experiments conducted on free-living wildlife demonstrating that predator-induced fear can cause cascading effects on the preys' resources and the surrounding landscape (Smith et al., 2017; Suraci et al., 2016, 2019a, 2019b; Zanette and Clinchy, 2020). Moreover, our total bout duration results, where the Swedish ungulates responded most strongly to human vocalizations, are in line with other studies that human-induced fear effects outweigh those of other predators (Zanette and Clinchy, 2020) (. In fact, several other playback experiments have demonstrated this effect of human vocalizations for carnivores in Europe and North America (Clinchy et al., 2016; Suraci et al., 2019b)), and diverse ungulates in South Africa (Zanette and Clinchy, 2020; Crawford et al., 2022) . This so-called human 'super predator' effect has been explained by recent analyses showing that, worldwide, humans kill herbivores and carnivores at greater rates than non-human predators (Darimont et al., 2015; Zanette and Clinchy, 2020).

Notably, previous experiments testing responses to dogs all demonstrate that hearing dogs barking either does not induce fear in wildlife (Suraci et al., 2019b), or has a very weak effect (Clinchy et al., 2016;
Crawford et al., 2022; Epperly et al., 2021), as our results indicate (Fig. 8). This result is somewhat surprising, especially for our study area where barking dogs are frequently used in hunting. One explanation for our study may lie in the fact that we did not use playbacks of the hunting dog breeds used in our area. However, this does not explain the lack of response to dog playbacks in an increasing number of studies from a variety of systems. All of these experiments utilized multiple exemplars of dog vocalizations drawn from different breeds, and one experiment (Suraci et al., 2019b) directly tested and demonstrated that individual cougars (Puma concolor) that had themselves been hunted using dogs, did not respond fearfully to hearing either large or small dogs. We currently lack a clear explanation for the absent, or weak, responses to dog sounds, although part of the explanation may lie in saying "barking dogs seldom bite". I.e., that across the multiple types of dogs present in most landscapes (including many non-hunting dogs) the barking of dogs generally does not associate with increased predation.

The fact that manipulating fear (perceived predation risk) influenced patch use by ungulates and also significantly reduced their impact on highly valuable crops, provides important knowledge regarding the process of applying the 'ecology of fear' as a management tool. How effective the use of fear is in reducing crop damage depends on minimizing habituation (Blumstein, 2016; Shivik, 2006; Zanette and Clinchy, 2020). In our study we managed to reduce crop damage during an important time for the farmer, i.e., the 4 weeks just before harvest. Habituation has been successfully avoided in similar experiments in wilderness areas for longer time periods (e.g. 4 weeks, (Suraci et al., 2016); 5 weeks, Suraci et al., 2019b) or entire breeding/growing seasons (e.g. 4 months, Zanette et al., 2011). Thus, there is a potential of protecting crops from grazing by ungulates for a longer period of time than we could show in this study. Furthermore, it has also been shown that fear can have major impacts on much larger areas than the spatial scale in our study (1 square km blocks in a study by Suraci et al., 2019a in the USA), pointing to the potential to induce fear and mitigate habituation at the whole field-level. Based on this 5 week, 1 square $\mathrm{km}$ study by Suraci et al. (2019a), the costs of providing crop protection could be as low as \$USD 15 ( $€$ 13.5) per ha for equipment and \$USD 3 ( $€ 2.7$ ) per ha per week for operating costs. However, replication of this work, and 


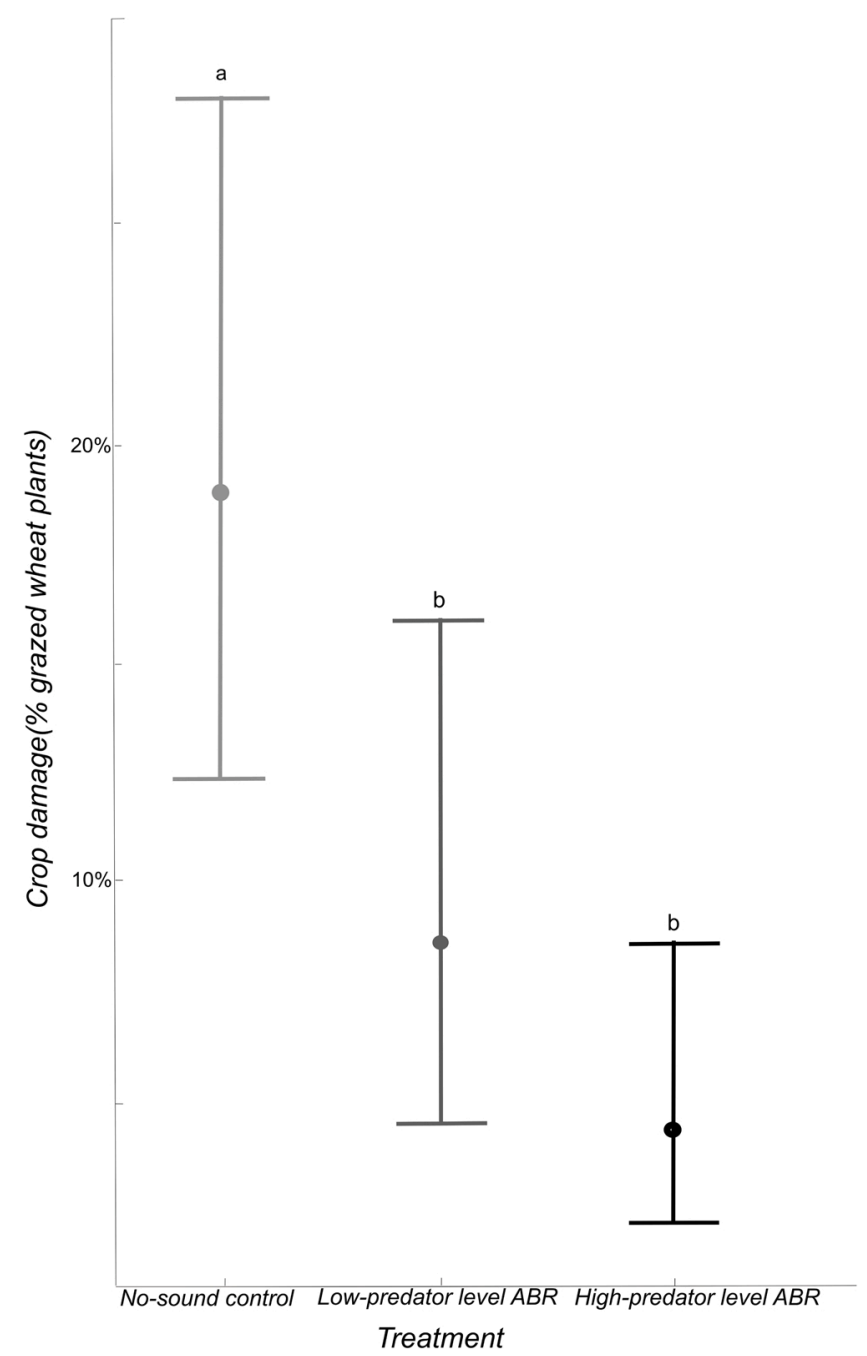

Fig. 7. Model prediction plot from a generalized linear mixed model showing the difference in crop damage between the three treatments during manipulation of predator vocalizations; no-sound control, low-predator level and highpredator level ABRs. Bars represent predictions $+95 \%$ confidence interval. Shared letters denote non-significant differences.

more rigorous costing in actual agricultural applications remains essential and costs may vary widely among systems depending on local labor costs and costs for material such as batteries.

\subsection{Conclusion and management recommendations}

In conclusion, our results contribute novel knowledge on how fear influences not only wildlife behavior, but also can modify their impact on the landscape. Furthermore, it provides insight and valuable components in assessing the potential of applying the 'ecology of fear' as a tool to mitigate human-wildlife conflicts. Hearing the vocalizations of the human 'super predator' (people speaking) is especially fearful and should thus be used when aiming to reduce ungulate use and damage on agricultural land. We recommend using exclusively human vocalizations in situations where ungulate densities are low or moderate. Earlier studies suggests that this could be effective throughout the entire growing season (Suraci et al., 2016; Zanette et al., 2011) at a whole-field level (Suraci et al., 2019b). When ungulate densities are likely to be high, it may be advisable to increase variation by adding the vocalizations of other predators to increase variation and thus reduce the probability of habituation. Our results regarding the reactions to non-human predator vocalizations suggests that wolf vocalizations may

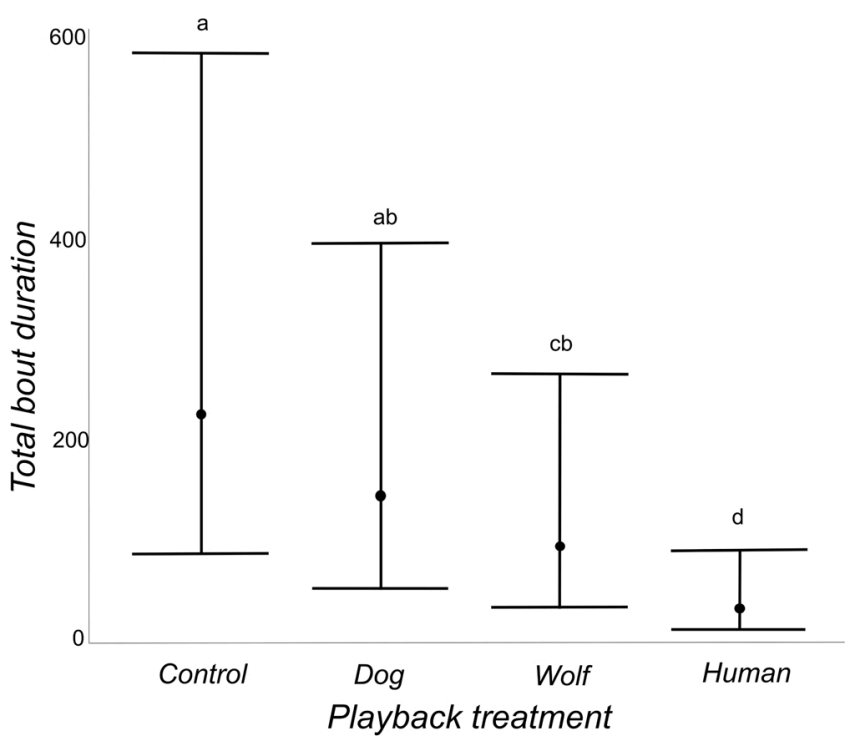

Fig. 8. Difference in total bout duration (seconds) of all ungulate species combined between the different playback treatments broadcasted by the ABRs. Squares in boxes represent mean value.

be more efficient than dog vocalizations, however, we need more tests to provide solid recommendations regarding the most frightening non-human predator vocalizations to include with human vocalizations.

\section{Declaration of Competing Interest}

The authors declare that they have no known competing financial interests or personal relationships that could have appeared to influence the work reported in this paper.

\section{Acknowledgments}

This study formed part of the research program "Beyond Moose ecology and management of multispecies ungulate systems", which was financially supported by the Swedish Environmental Protection Agency (Naturvårdsverket, NV-01337-15/NV-03047-16/NV-08503-18), Kempestiftelserna (JCK-1514), the Swedish Association for Hunting and Wildlife Management (grant 5855/2015), and Västerbotten County's Älgvårdsfonden (no. 218-9314-15). We would like to thank the landowners for giving the permission of conducting this study on your fields. Further, we would like to thank game managers, forest managers and agricultural managers for valuable insights and help in the field. We are grateful for the help from Tovetorp research station and Edeby ripsa viltforvaltning that gave us the opportunity to conduct a first trial on your land. We thank Ingemar Parck and Carolin Berndt for assisting during field-work. The study was financed by Stina Werners Fund (2019047). Funding for contributions of Michael Clinchy and Liana Zanette is thanks to the Natural Sciences and Engineering Research Council of Canada. AMF was funded by the Swedish Research Council for Sustainable Development (FR-2016/0005).

\section{Appendix A. Supporting information}

Supplementary data associated with this article can be found in the online version at doi:10.1016/j.agee.2022.107853.

\section{References}

Apollonio, M., Andersen, R., Putman, R., 2010a. Present status and future challenges for European ungulate management. In: Apollonio, M., Andersen, R., Putman, R. (Eds.), European Ungulates and their Management in the 21st Century. Cambridge 
University Press, Cambridge, UK, pp. 578-604. In M. Apollonio, R., Andersen, R., Putman, R. (eds.).

Apollonio, M., Andersen, R., Putman, R. (Eds.), 2010b. European Ungulates and their Management in the 21st Century. Cambridge University Press, Cambridge, UK, p. 604.

Bates, D., Mächler, M., Bolker, B.M., Walker, S.C., 2015. Fitting linear mixed-effects models using lme4. arXiv preprint arXiv:1406.5823.

Bleier, N., Kovács, I., Schally, G., Szemethy, L., Csányi, S., 2017. Spatial and temporal characteristics of the damage caused by wild ungulates in maize (Zea mays L.) crops. Int. J. Pest Manag. 63, 92-100. https://doi.org/10.1080/09670874.2016.1227487.

Blumstein, D.T., 2016. Habituation and sensitization: new thoughts about old ideas. Anim. Behav. 120, 255-262. https://doi.org/10.1016/j.anbehav.2016.05.012.

Blumstein, D.T., Daniel, J.C., 1995. Isolation from mammalian predators differentially affects two congeners. Behav. Ecol. 13, 657-663.

Borkowski, Jakub, Pudelko, Marek, 2007. Forest habitat use and home-range size in radio collared fallow deer. Annales Zoologici Fennici 107-114.

Bouskila, A., Blumstein, D.T., 1992. Rules of thumb for predation hazard assessment: predictions from a dynamic model. Am. Nat. 139, 161-176.

Brown, J.S., Laundré, J.W., Gurung, M., 1999. The ecology of fear: optimal foraging, game theory, and trophic interactions. J. Mammal. 80, 385-399. https://doi.org/ $10.2307 / 1383287$.

Bubnicki, J.W., Churski, M., Kuijper, D.P.J., 2016. TRAPPER: an open source web-based application to manage camera trapping projects. Methods Ecol. Evol. 7, 1209-1216. https://doi.org/10.1111/2041-210X.12571.

Bubnicki, J.W., Churski, M., Schmidt, K., Diserens, T.A., 2019. Linking spatial patterns of terrestrial herbivore community structure to trophic interactions. ELife 8, e44937. https://doi.org/10.7554/eLife.44937.

Ciuti, S., Davini, S., Luccarini, S., Apollonio, M., 2003. Variation in home range size of female fallow deer inhabiting a sub-mediterranean habitat. Rev. d'Ecologie (La Terre la Vie) 58, 381-395.

Clinchy, M., Zanette, L.Y., Roberts, D., Justin, P., Newman, C., Macdonald, D.W., 2016. Fear of the human "super predator" far exceeds the fear of large carnivores in a model mesocarnivore. Behav. Ecol. 27, 1826-1832. https://doi.org/10.1093/ beheco/arw117.

Crawford, D.A., Conner, L.M., Clinchy, M., Zanette, L.Y., Cherry, M.J., 2022. Prey tells, large herbivores fear the human 'super predator'. Oecolgia. https://doi.org/ 10.1007/s00442-021-05080-w.

Creel, S., Christianson, D., 2008. Relationships between direct predation and risk effects. Trends Ecol. Evol. 4, 194-201. https://doi.org/10.1016/j.tree.2007.12.004.

Creel, S., Winnie, J.A., 2005. Responses of elk herd size to fine-scale spatial and temporal variation in the risk of predation by wolves. Anim. Behav. 5, 1181-1189. https://doi. org/10.1016/j.anbehav.2004.07.022.

Cromsigt, J.P.G.M., Kuijper, D.P.J., Adam, M., Beschta, R.L., Churski, M., Eycott, A., Kerley, G.I.H., Mysterud, A., Schmidt, K., West, K., 2013. Hunting for fear: innovating management of human - wildlife conflicts. J. Appl. Ecol. 3, 544-549. https://doi.org/10.1111/1365-2664.12076.

Darimont, C.T., Fox, C.H., Bryan, H.M., Reimchen, T.E., 2015. The unique ecology of human predators. Science 349, 858-861. https://doi.org/10.1126/science.aac4249.

Davini, S., Ciuti, S., Luccarini, S., Apollonio, M., 2004. Home range patterns in a subMediterranean habitat Home range patterns of male fallow deer Dama dama in a sub-Mediterranean habitat. Acta Theriol. 49, 393-404. https://doi.org/10.1007/ BF03192537.

Durant, S.M., 2000. Living with the enemy: avoidance of hyenas and lions by cheetahs in the Serengeti. Behav. Ecol. 11, 624-632. https://doi.org/10.1093/beheco/11.6.624.

Ekman, H., 2010. Vargen-den jagade jägaren, first ed. Nordstedts, Stockholm.

Enos, J.K., Ward, M.P., Hauber, M.E., 2021. A review of the scientific evidence on the impact of biologically salient frightening devices to protect crops from avian pests. Crop Prot., 105734 https://doi.org/10.1016/j.cropro.2021.105734.

Epperly, H.K., Clinchy, M., Zanette, L.Y., McCeery, R.A., 2021. Fear of large carnivores is tied to ungulate habitat use: evidence from a bifactorial experiment. Sci. Rep. 11, 1-11. https://doi.org/10.1038/s41598-021-92469-5.

Ferretti, F., Lovari, S., 2014. Introducing aliens: problems associated with invasive exotics. Behav. Manag. Eur. Ungulat-.-. 78-109.

Garvey, P.M., Banks, P.B., Suraci, J.P., Bodey, T.W., Glen, A.S., Jones, C.J., McArthur, C., Norbury, G.L., Price, C.J., Russell, J.C., Sih, A., 2020. Leveraging motivations, personality, and sensory cues for vertebrate pest management. Trends Ecol. Evol. 35, 990-1000. https://doi.org/10.1016/j.tree.2020.07.007.

Gaynor, K.M., Cherry, M.J., Gilbert, S.L., Kohl, M.T., Larson, C.L., Newsome, T.M., Prugh, L.R., Suraci, J.P., 2020. An applied ecology of fear framework: linking theory to conservation practice. Anim. Conserv. 24, 1-14. https://doi.org/10.1111/ acv.12629.

Geisser, H., Reyer, H.-U., 2004. Efficacy of hunting, feeding, and fencing to reduce crop damage by wild boars. J. Wildl. Manag. 68, 939-946. https://doi.org/10.2193/ 0022-541x(2004)068[0939:eohfaf]2.0.c0;2.

Hettena, A.M., Munoz, N., Blumstein, D.T., 2014. Prey responses to predator's sounds: a review and empirical study. Ethology 120, 427-452. https://doi.org/10.1111/ eth.12219.

Johnson, D.D.P., Blumstein, D.T., Fowler, J.H., Haselton, M.G., 2013. The evolution of error: error management, cognitive constraints, and adaptive decision-making biases. Trends Ecol. Evol. 28, 474-481. https://doi.org/10.1016/j.tree.2013.05.014.

Jordbruksverket, 2020a. Jordbruksmarkens användning 2020. Slutlig statistik. JO0104.

Jordbruksverket, 2020b. Jordbruksmarkens användning 2020. Sveriges officiella statistik. JO10SM 2011.

Jordbruksverket, 2020c. Skörd av spannmål, trindsäd, oljeväxter, potatis och slåttervall 2020. Slutlig statistik. JO0601. https://statistik.sjv.se/PXWeb/pxweb/sv/Jordbr
uksverkets\%20statistikdatabas/Jordbruksverkets\%20statistikdatabas_Skordar /JO0601J01.px/ (Accessed 21 April 2021).

Kuijper, D.P.J., Verwijmeren, M., Churski, M., Zbyryt, A., Schmidt, K., 2014. What cues do ungulates use to assess predation risk in dense temperate forests ? PLoS 9, 1-12. https://doi.org/10.1371/journal.pone.0084607.

Länsstyrelserna , 2021. Statistik älgdata. 〈https://algdata-apps.lansstyrelsen.se/ algdata-apps-stat $\rangle$ (Accessed 18 April 2021).

Lima, S.L., Dill, L.M., 1990. Behavioral decisions made under the risk of predation: a review and prospectus. Can. J. Zool. 68, 619-640.

Linnell, J.D.C., Cretois, B., Nilsen, E.B., Rolandsen, C.M., Solberg, E.J., Veiberg, V., Kaczensky, P., Moorter, B., Van, Panzacchi, M., Rauset, G.R., Kaltenborn, B., 2020. The challenges and opportunities of coexisting with wild ungulates in the humandominated landscapes of Europe' s Anthropocene. Biol. Conserv. 244, 108500 https://doi.org/10.1016/j.biocon.2020.108500.

Marchiori, E., Sturaro, E., Ramanzin, M., 2012. Wild red deerc (Cervus ela-phus L.) grazing may seriously reduce forage production in mountain meadows. Ital. J. Anim. Sci. 11, 47-53. https://doi.org/10.4081/ijas.2012.e9.

McNamara, J.M., Houston, I., 1992. Risk-sensitive foraging: theory. Bull. Math. Biol. 54, 355-378.

Menichetti, L., Touzot, L., Elofsson, K., Hyvönen, R., Kätterer, T., Kjellander, P., 2019. Interactions between a population of fallow deer (Dama dama), humans and crops in a managed composite temperate landscape in southern Sweden: conflict or opportunity? PLoS One 14, 1-17. https://doi.org/10.1371/journal.pone.0215594.

Presley, S.J., Cisneros, L.M., Klingbeil, B.T., Willig, M.R., 2019. Landscape ecology of mammals 100, 1044-1068. doi: 10.1093/jmammal/gyy169.

R Core Team, 2013. R: A Language and Environment for Statistical Computing. R Foundation for Statistical Computing, Vienna, Austria. http://www.R-project.org/.

Ravenelle, J., Nyhus, P.J., 2017. Global patterns and trends in human - wildlife conflict compensation. Conversat. Biol. 31, 1247-1256. https://doi.org/10.1111/ cobi.12948.

Reimoser, F., Putman, R., 2014. Impacts of wild ungulates on vegetation: costs and benefits. Ungulate Management in Europe: Problems and Practices. Cambridge University Press, Cambridge, pp. 144-191. https://doi.org/10.1017/ CBO9780511974137.007.

Schley, L., Roper, T.J., 2003. Diet of wild boar Sus scrofa in Western Europe, with particular reference to consumption of agricultural crops. Mammal. Rev. 33, 43-56. https://doi.org/10.1046/j.1365-2907.2003.00010.x.

Shivik, J.A., 2006. Tools for the edge: what's new for conserving carnivores. Bioscience 56, 253-259. https://doi.org/10.1641/0006-3568(2006)056[0253:TFTEWN]2.0 $\mathrm{CO} ; 2$.

Smith, J.A., Suraci, J.P., Clinchy, M., Crawford, Ayana, Roberts, Devin, Zanette, L.Y., Wilmers, C.C., Crawford, A., Roberts, D., Ly, Z., Smith, J.A., 2017. Fear of the human 'super predator' reduces feeding time in large carnivores. Proc. R. Soc. B: Biol. Sci. 284, 20170433 https://doi.org/10.1098/rspb.2017.0433.

Smith, J.A., Suraci, J.P., Hunter, J.S., Gaynor, K.M., Keller, C.B., Palmer, M.S., Atkins, J. L., Castañeda, I., Cherry, M.J., Garvey, P.M., Huebner, S.E., Morin, D.J., Teckentrup, L., Weterings, M.J.A., Beaudrot, L., Smith, J.A., 2020. Zooming in on mechanistic predator - prey ecology: Integrating camera traps with experimental methods to reveal the drivers of ecological interactions. J. Anim. Ecol. 89, 1997-2012. https://doi.org/10.1111/1365-2656.13264.

Suraci, J.P., Clinchy, M., Dill, L.M., Roberts, D., Zanette, L.Y., 2016. Fear of large carnivores causes a trophic cascade. Nat. Commun. 7, 1-7. https://doi.org/10.1038/ ncomms10698.

Suraci, J.P., Clinchy, M., Mugerwa, B., Delsey, M., Macdonald, D.W., Smith, J.A., Wilmers, C.C., Zanette, L.Y., 2017. A new Automated Behavioural Response system to integrate playback experiments into camera trap studies. Methods Ecol. Evol. 8, 957-964. https://doi.org/10.1111/2041-210X.12711.

Suraci, J.P., Clinchy, M., Zanette, L.Y., Wilmers, C.C., 2019a. Fear of humans as apex predators has landscape-scale impacts from mountain lions to mice. Ecol. Lett. 22, 1578-1586. https://doi.org/10.1111/ele.13344.

Suraci, J.P., Smith, J.A., Clinchy, M., Zanette, L.Y., Wilmers, C.C., 2019b. Humans, but not their dogs, displace pumas from their kills: an experimental approach. Sci. Rep. 9, 1-8. https://doi.org/10.1038/s41598-019-48742-9.

Svenska Jägareförbundet, 2021. Viltdata. 〈https://rapport.viltdata.se/statistik/ (Accessed 18 April 2021).

Swedish Meteorological and Hydrological Institute (SMHI) 2021. Månads-, årstids- och årskartor. 〈https://www.smhi.se/data/meteorologi/kartor〉 (Accessed 17 April 2021).

Thulin, C., Malmsten, J., Ericsson, G., 2015. Opportunities and challenges with growing wildlife populations and zoonotic diseases in Sweden. Eur. J. Wildl. Res. 61, 649-656. https://doi.org/10.1007/s10344-015-0945-1.

Thuppil, V., Coss, R.G., 2016. Playback of felid growls mitigates crop-raiding by elephants Elephas maximus in southern India. Oryx 50, 329-335. https://doi.org/ 10.1017/S0030605314000635.

van Beeck Calkoen, S.T., Kreikenbohm, R., Kuijper, D.P., Heurich, M., 2021. Olfactory cues of large carnivores modify red deer behavior and browsing intensity. Behav. Ecol. https://doi.org/10.1093/beheco/arab071.

Zanette, L.Y., Clinchy, M., 2020. Ecology and neurobiology of fear in free-living wildlife. Annu. Rev. Ecol. Evol. Syst. 51, 297-318. https://doi.org/10.1146/annurev-ecolsys011720-124613.

Zanette, L.Y., White, A.F., Allen, M.C., Clinchy, M., 2011. Perceived predation risk reduces the number of offspring songbirds produce per year. Science 334, 1398-1401. https://doi.org/10.1126/science.1210908. 